\title{
Identification of Leishmania chagasi from skin in Leishmania/HIV co-infection: a case report
}

\author{
Identificação de Leishmania chagasi na pele em co-infecção \\ Leishmania/HIV: relato de caso
}

\begin{abstract}
Marcela Orsini ${ }^{1,2}$, Marcelo Silva ${ }^{3}$, Zélia Maria Profeta da Luz ${ }^{1}$, Jolandt Disch ${ }^{1}$, Octávio Fernandes ${ }^{4}$, Dalton Moreira ${ }^{5}$, Antonio Carlos Martins Guedes ${ }^{6}$ and Ana Rabello ${ }^{1}$
\end{abstract}

\begin{abstract}
A case of HIVLeishmania co-infection presenting both visceral and cutaneous manifestations is reported. Leishmania infection was confirmed by conventional methods (parasitological approach and serology) and by PCR. Leishmania chagasi isolated from the skin lesion was characterized by enzyme electrophoresis and by restriction fragment length polymorphism of the internal transcribed spacer of the ribosomal gene.
\end{abstract}

Key-words: Leishmania. HIV.

Resumo É descrito um caso de co-infecção Leishmania/HIV com manifestações cutâneas e visceral. Infecção pela leishmania foi confirmada através de métodos convencionais (parasitológicos e sorológicos) e através da PCR. A espécie Leishmania chagasi isolada da pele foi caracterizada por eletroforese enzimática e por polimorfismo de fragmento obtido por enzima de restrição.

Palavras-chaves: Leishmania. HIV.

Co-infection by Leishmania spp and HIV has been considered an emerging disease in several parts of the world ${ }^{11}$. In Brazil, more than 200,000 cases of leishmaniasis have been notified over the last decade 1 . Between 1980 and 1991, the Brazilian Ministry of Health recorded an annual mean of 27,000 new cases of cutaneous (CL) and muco-cutaneous leishmaniasis (ML) and 2,800 new cases of visceral infection. These figures in the annual reports have increased during the past three years reaching 35000 cases of $\mathrm{CL}$ and 3,500 patients with visceral leishmaniasis $(\mathrm{VL})^{3}$. In Minas Gerais state, records have shown 1569 cases of VL (population of 15 million people), 30\% (445) of which were from the metropolitan region.

Growth of the Brazilian population, acceleration of urbanization processes, man-made environmental changes and rural-urban migration contributed to the increased and modified geographic spread of
Leishmania spp parasite. Such that, nowadays many people living in dense urban zones live in contact with the causative agent. During the past decade, many urban outbreaks of VL caused by Leishmania (Leishmania) chagasi have been reported in Brazil ${ }^{10}$.

Despite of the reduction in mortality after the introduction of anti-HIV drugs, recent data suggest that the AIDS epidemic is still spreading among the Brazilian population, reaching small cities, affecting women in the same frequency as men and extending to less educated populations. According to the National AIDS Program of the Brazilian Ministry of Health, 215,810 cases of AIDS had been notified up until November 1999 , with an incidence rate of $90 / 100,000$ inhabitants. Approximately 114,500 (50\% of the reported cases) cumulative deaths secondary to AIDS were recorded by 2001 (Boletim Epidemiológico AIDS, 2001).

\footnotetext{
1. Laboratório de Pesquisas Clínicas do Centro de Pesquisas René Rachou da Fundação Oswaldo Cruz, Belo Horizonte, MG. 2. Curso de Pós Graduação em Medicina Tropical da Universidade Federal de Minas Gerais, Belo Horizonte, MG. 3. Clínica Integrada de Infectologia do Hospital Santo Ivo, Belo Horizonte, MG. 4. Departamento de Imunologia e Medicina Tropical do Instituto Oswaldo Cruz da Fundação Oswaldo Cruz, Rio de Janeiro, RJ. 5. Centro de Referência e Treinamento em Doenças Infecto-Parasitárias Orestes Diniz da Universidade Federal de Minas Gerais, Belo Horizonte, MG. 6. Faculdade de Medicina da Universidade Federal de Minas Gerais, Belo Horizonte, MG.

Endereço para correspondência: Dra. Marcela Orsini. Laboratório de Pesquisas Clínicas/CPqRR/FIOCRUZ. Av. Augusto de Lima 1715, 30190-002 Belo Horizonte, MG, Brazil.

Tel: 5531 3295-3566, Fax: 5531 3295-3115.

E-mail: orsini@cpqrr.fiocruz.br

Recebido para publicação em 21/12/2000.
} 
According to estimates of the World Health Organization (WHO), 2-9\% of the South European AIDS patients develop VL. Gradoni et al ${ }^{5}$ observed a 500 times higher prevalence of Leishmania spp infection among HIV infected subjects in Sicily.

In Brazil, out of 61 actively searched Leishmania/ HIV co-infected cases, $64 \%$ were CL or ML and $36 \%$ presented the visceral form of the disease. In only nine patients the Leishmania species was characterized and in all cases belonged to the Viannia subgenus (A. Rabello: personal communication, 1999).

This paper reports a fatal case of Leishmania/HIV co-infection presenting both cutaneous and visceral manifestations that were caused by Leishmania (Leishmania) chagasi.

\section{CASE REPORT}

In December 1995, after successive episodes of sinusitis and pneumonia, HIV infection was diagnosed in a 43-year-old patient from Belo Horizonte, Minas Gerais State, Brazil. HIV serology was performed by ELISA and confirmed by Western Blot. At that time, the patient presented a good healthy condition and clinical manifestation of seborrheic dermatitis.

In January 1996, with 87 CD4 positive lymphocyte/ $\mathrm{mm}^{3}$ and viral load of 73,000 RNA copies $/ \mathrm{ml}$, the patient received zidovudine, didanosine and trimethoprimsulfamethoxazole. Clinical conditions remained unchanged until March 1997, when the patient presented fever $\left(38^{\circ} \mathrm{C}\right)$, weight loss $(7.5 \mathrm{~kg})$ and splenomegaly. Investigation of the putative etiology of the fever of unknown origin was not successful. X-ray and computerized tomography of the thorax and abdominal ultrasonography were normal, as well as the otorhinolaryngology exam. Urine and blood laboratory analysis also did not reveal any abnormalities. Serology for CMV infection, Epstein-Barr virus infection, syphilis, brucellosis and toxoplasmosis were negative. Microbiologic culture of urine and faeces and investigation of Mycobacterium sp were negative. Direct examination of the bone marrow showed no pathologic abnormalities. Anti-retroviral therapy was changed to stavudine and lamivudine which induced clinical improvement with reduction of the spleen size and regression of the fever leading to the patient's return to normal daily activities.

In January 1998, the patient presented diarrhea and Shigella sp and Cryptosporidium $s p$ were identified in the feces. Treatment (floxacillin for 15 days) was considered successful. One month later, there was a progressive worsening of symptoms, with alopecia, caquexia and peripheral neuritis.

In August 1998, the patient presented pancytopenia (platelets: 34,000/ml, leukocytes: 1,200/ml, granulocytes: 700/ml, hemoglobin: $8.1 \%$ ) and alterations in several biochemical parameters (aspartate aminotransferase: $71 \mathrm{mg} \%$, alanine aminotransferase: $40 \mathrm{mg} \%$, alkaline phosphatase: $150 \mathrm{mg} \%$, prothrombin activity: $85 \%$ ) were observed. In December, 1998, cutaneous and oral-pharyngeal lesions suggestive of herpes zoster, appeared. Fluconazole and acyclovir acheived total recovery of the oral-pharyngeal lesions and partial recovery of the cutaneous lesions was observed after 14 days of treatment. However, the cutaneous hyperkeratosis lesions did not heal completely and a biopsy was taken in June 1999. Although initial histopathological diagnosis of keratoacanthoma was not confirmed, during a microscopic revision of the slides Leishmania spp amastigotes were found in the interior of macrophages in a mild lymphohistiocytary inflammatory dermal infiltrate (Figure 1). In August, the patient presented new cutaneous lesions located in the upper and lower limbs and hepatosplenomegaly. A skin biopsy from the new lesions was performed and Leishmania spp was detected by imprint and culture. Hemoculture and PCR using DNA extracted from peripheral mononuclear cells or skin with a set of primers directed towards the minicircle conserved region, were positive. Parasites isolated from the biopsy specimen were submitted to in vitro culture and DNA was extracted. Electrophoresis of parasite enzymes identified $L$. chagasi as the causative agent. Restriction fragment length polymorphism of amplicons corresponding to the internal transcribed spacers of the ribosomal gene confirmed this finding (Figure 2).

Treatment with meglumine antimoniate $(10 \mathrm{mg} / \mathrm{kg}$ for 40 days) was initiated and lead to partial improvement of the skin lesions, regression of the hepatosplenomegaly and negative hemoculture. In November the patient was hospitalized, presenting fever, progressive dyspnea, caquexia and disseminated cutaneous lesions. Supportive measures were implemented, but nevertheless the patient died on December $7^{\text {th }}$.

\section{DISCUSSION}

Both AIDS and leishmaniasis are highly prevalent in Brazil and the number of cases of co-infections is growing $^{9}$ In the immune competent patient $\mathrm{CL}$ is commonly characterized by a single ulcer that responds satisfactorily to treatment. Cure is assured for $95 \%$ of the patients for whom treatment has been applied in time $^{6}$. Cure and resistance to infection demands an adequate cellular immune response of the Th1 type, with production of gamma-interferon and IL-12. The infection leads to disease and its complications when a cellular immune response of the type Th2 is elicited ${ }^{9}$. Similarly the development of AIDS in an HIV infected patient is associated with a Th2 profile. HIV-Leishmania coinfection favors the Th2 response with consequent aggravation of both infections. 


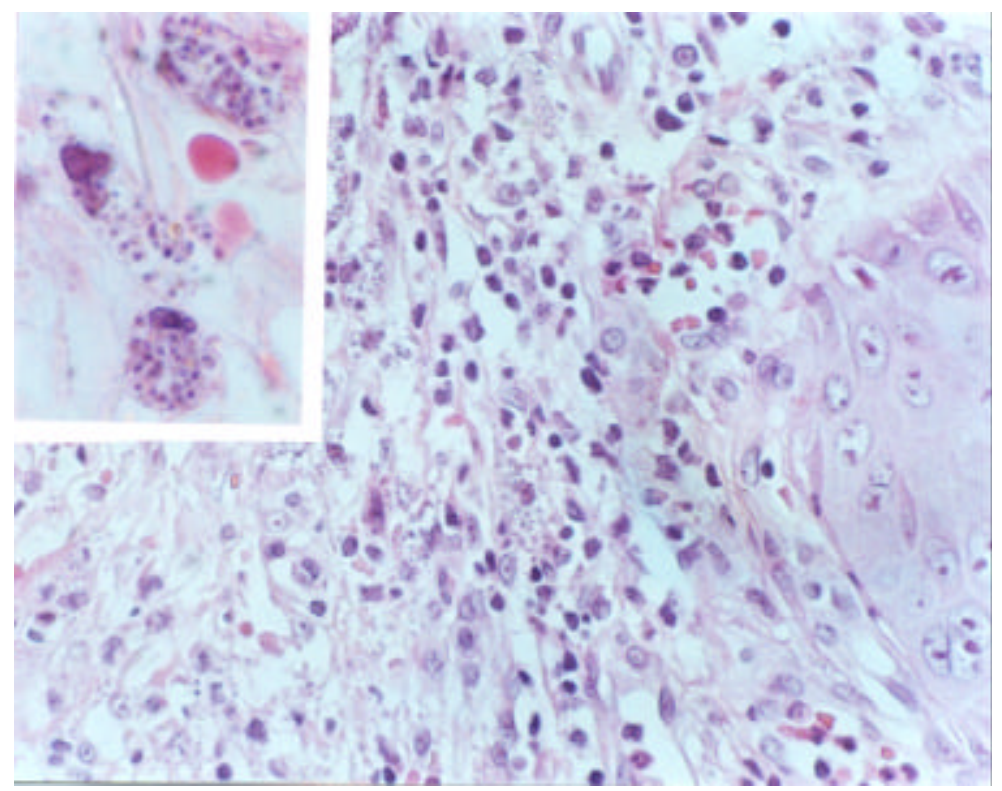

Figure 1 - Lymphohistiocytary inflammatory infiltrate in the dermal surface with amastigotes in the interior of macrophages (HE, 400X). On the left corner, macrophages with amastigotes (HE, 1000X).

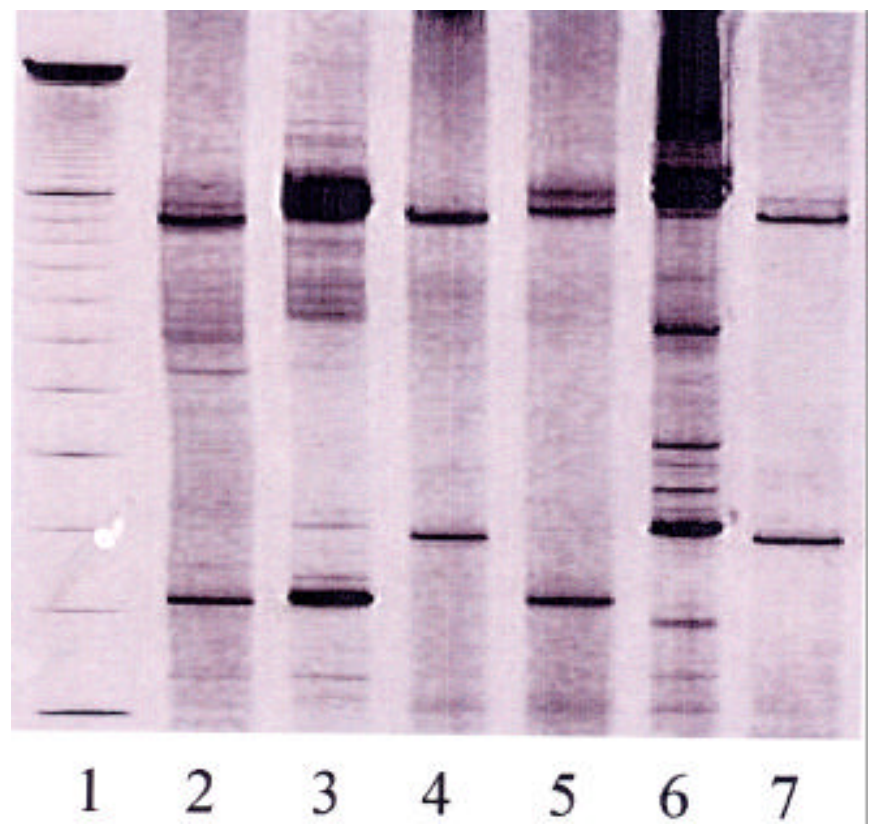

Figure 2 - Profiles of Ecor-I amplified KDNA of Leishmania spp: Lane 1: 100 bp ladder. Lane 2: L. lainsoni. Lane 3: L. guyanensis. Lane 6: L. mexicana. Lane 7: L. chagasi.

The patient here described presented cutaneous and visceral manifestation. Initial confirmation of infection by Leishmania spp was performed by microscopic examination of the skin biopsy. Cutaneous manifestations of $L$. chagasi in HIV infected patients has been observed by several other authors ${ }^{248}$.
In this patient, the diagnosis of leishmaniasis was not anticipated. Spleen enlargement was attributed to specific reaction to HIV and/or drugs and Leishmania spp amastigotes were not identified at pathologic examination. Treatment of the Leishmania infection was 
therefore delayed leading to aggravation of the patient's situation. The described case illustrates the severity of an association of Leishmania spp infection and HIV and underlines the need for inclusion of Leishmania spp evaluation in AIDS patients in regions where leishmaniasis occurs.

\section{REFERENCES}

1. Alvar J, Canavate C, Gutierrez-Solar B, Jimenez M, Laguna F, Lopez-Velz R, Molina R, Moreno J. Leishmania and Human Immunodeficiency Virus coinfection: the first 10 years. Clinical of Microbiology Reviews 298-318, 1997.

2. Dauden E, Fernadez-Penaz P, Rios L. Leishmaniasis presenting as a dermatomyositis-like syndrome in AIDS. Journal of American Academy of Dermatology 35, 316-319, 1996.

3. Fundação Nacional de Saúde, Informe Epidemiológico do Sistema Unico de Saúde, Ministério da Saúde, Brasília - Brasil, 2000.

4. Gonzalo HC, Arazo GP, Alvarez CG, Alonso CF, Jorda RP, Aguirre EJM. Leishmaniasis visceral e infección por el HIV: dos nuevos casos. Annals of Medicine Interna 8: 208-209, 1991.

5. Gradoni L, Scalone A, Gramiccia M, Troiani M. Epidemiological surveillance of leishmaniasis in HIV-1-infected individuals in Italy. AIDS 10:785-791, 1996

6. Marzochi MCA. Leishmanioses no Brasil: as leishmanioses tegumentares. Jornal Brasileiro de Medicina, 63: 82-99, 1992.

7. Passos VMA, Falcão, AL, Mazorchi MCA, Gontijo CMF, Dias ES, Barbosa-Santos EGO, Guerra HL, Katz N. Epidemiological aspects of American Cutaneous Leishmaniasis in a periurban area of the metropolitan region of Belo Horizonte, Minas Gerais, Brazil, Memórias do Instituto Oswaldo Cruz 88: 103-110, 1993

8. Postigo C, Liamas R, Zarco C, Rubio R, Pulido F, Costa JR, Iglesias L. Cutaneous lesions in patients with visceral leishmaniasis and HIV infection. Journal of Infection 35: 265-268, 1997.

9. Rabello A, Andrade MO, Dish J. Co-infecção Leishmania/ HIV. Revista da Sociedade Brasileira de Medicina Tropical 31 (supl III): 81, 1998.

10. Vasconcelos IAB, Vasconcelos AW, Momen H, Grimaldi Jr G, Alencar JE. Epidemiological studies on american leishmaniasis in Ceará State, Brazil molecular characterization of the Leishmania isolates. Annals of Tropical Medicine and Parasitology 82: 547-554, 1988.

11. World Healh Organization. Division of Control of Tropical Diseases. Epidemiological analyses of retrospective cases of Leishmania/HIV co-infection. World Health Organization/LEISH/ 96.39.1996. 